\title{
PENGARUH LATIHAN ROM TERHADAP KEKUATAN OTOT PADA PASIEN STROKE DI RUANG FLAMBOYAN RSUD MUHAMMAD SANI
}

\author{
Rizki Sari Utami Muchtar ${ }^{1}$, Siska Natalia ${ }^{2}$, Juliana ${ }^{3}$ \\ 1,2,3 STIKes Awal Bros Batam \\ Email : sariutami0784@gmail.com
}

\begin{abstract}
ABSTRAK
Mayoritas pasien stroke mengalami kelemahan pada otot, adapun keterbatasan pergerakan dapat memperparah kondisi muskuloskletal dan mempercepat penurunan kekuatan otot pada pasien stroke. Untuk itu perlu penanganan rehabilitasi segera mungkin dengan melakukan latihan pergerakan otot (Range Of Motion). Adapun tujuan penelitian ini untuk mengetahui pengaruh Latihan Range Of Motion Terhadap Kekkuatan Otot Pada pasien Stroke. Jenis penelitian ini adalah penelitian kuantitatif dengan metode Quasy Experiment (pre and post test without control). Sampel dalam penelitian ini terdiri dari 20 responden stroke dan data dianalisa menggunakan uji Wilcoxon Rank Test untuk eksteremitas atas dan Paired T Test untuk eksteremitas bawah. Hasil diketehui bahwa pada eksteremitas atas nilai $p$-value sebesar $0,000(\mathrm{p}=<0,05)$ sedangkan pada eksteremitas bawah nilai p-value sebesar $0,000 \quad(\mathrm{p}=<0,05)$ yang menunjukkan ada pengaruh latihan Range Of Motion terhadap kekuatan otot eksteremitas atas dan bawah pasien stroke.
\end{abstract}

Kata kunci :Stroke, Range Of Motion, Kekuatan Otot

\begin{abstract}
Majority of stroke patients had weakness in the muscles, the limitation of movement and reduced joint use can worsen the musculoskletal and accelerate the decrease in muscle strength in stroke patients. For this reason, rehabilitation needs to be handled as soon as possible, one of which is to do muscle movement exercises (Range of Motion). The purpose of this study was to determine the effect of Range of Motion Exercise on Muscle Strength in Stroke Patients. The type of this research was quantitative research with Quasy Experiment (pre and post test research design without control). The sample in this study consisted of 20 stroke respondents and the data were analyzed using the Wilcoxon Rank Test for upper extremities and Paired T Test for lower extremities. The results found that the extremity of the p-value of $0,000(p=<0.05)$ whereas the lower extremity ( $p$-value of 0,000 $(p=<0.05)$ showed the effect of Range of Motion exercise on the muscle strength of the extremity of stroke patients.
\end{abstract}

Keywords :Stroke, Range Of Motion, Muscular strength 


\section{PENDAHULUAN}

Menurut (AHA, 2015) Stroke secara umum terbagi menjadi dua Jenis yaitu stroke hemoragi dan non hemoragi (iskemik). Stroke hemoragi ialah stroke yang disebabkan oleh pecahnya pembulu darah dalam otak yang terjadi di daerah tertentu sehingga memenuhi jaringan otak, perdarahan ini disebabkan oleh adanya perdarahan di intra selebral atau perdarahan subarakhroid (AHA, 2015).

Stroke merupakan salah satu penyebab gangguan aktivitas fungsional seperti hemiparalisis, kelemahan, hilangnya sensasi pada wajah, lengan atau tungkai di salah satu sisi tubuh, kesulitan berbicara atau memahami, kesulitan menelan, dan hilangnya sebagain penglihatan di satu sisi (Irfan, 2010).

Salah satu solusi tahap awal adalah melatih pergerakan otot (Range Of Motion) pada ekstermitas yang lemah atau lumpuh agar menjadi kuat sehingga pasien pasca stroke dapat mengerakkan ektermitasnya, selain itu latihan Range Of Motion dapat mencegah terjadinya atropi otot, meningkatkan peredaran darah ke ekstremitas, mengurangi kelumpuhan vaskcular, memberikan kenyamanan dan juga dapat menghindari adanya komplikasi akibat kurang gerak seperti kontraktur dan kekakuan sendi pada pasien pasca stroke (Wirawan,2009)

Range Of Motion (ROM) adalah latihan yang dilakukan untuk mempertahankan atau memperbaiki tingkat kesempurnaan kemampuan pergerakkan sendi secara normal dan lengkap untuk meningkatkan massa otot dan tonus otot. Melakukan mobilisasi persendian dengan latihan ROM dapat mencegah berbagai komplikasi seperti nyeri karena tekanan, kontraktur, tromboplebitis, dekubitus sehingga mobilisasi dini penting dilakukan secara rutin dan kontinyu. Memberikan latihan secara dini dapat meningkatkan kekuatan otot karena dapat menstimulasi motor unit sehingga semakin banyak motor unit yang terlibat maka akan terjadi peningkatan kekuatan otot, kerugian pasien hemiparese bila tidak segera ditangani maka akan terjadi kecacatan yang permanen (Potter \& Perry, 2009).

Manfaat Range Of Motion (ROM) adalah untuk menentukan nilai kemampuan sendi tulang dan otot daam melakukan pergerakan, memperbaiki tonus otot, memperbaiki toleransi otot untuk latihan, mencegah terjadinya kekakuan sendi, memperlancar sirkulasi darah dengan dilakukannya latihan Range of Motion (ROM) pada pasien (Hardwick \& Lang, 2012).

Penelitian yang dilakukan Anita (2018) yang bertujuan untuk mengetahui adanya pengaruh latihan Range $O f$ Motion terhadap rentang gerak sendi ekstremitas atas pada pasien pasca stroke. Hasil penelitian menunjukkan data dianalisis dengan menggunakan uji statistic yaitu uji Wilcoxon dengan tingkat kemaknaan 
$a=0,05$. Diperoleh nilai sendi peluru fleksi dan ekstensi $\mathrm{p}=0,000$, sendi engsel fleksi dan ekstensi $\mathrm{p}=0,000$, sendi kondiloid fleksi dan ekstensi nilai $\mathrm{p}=0,000$ dengan interprestasi nilai $\mathrm{p}<0,05$, maka dapat disimpulkan bahwa hipotesis alternatif (Ha) diterima dan hipotesis nol (Ho) ditolak artinya ada pengaruh latihan Range Of Motion terhadap rentang gerak sendi ekstremitas atas pada pasien pasca stroke di Makassar.

Hasil observasi peneliti terhadap sepuluh pasien stroke didapatkan bahwa mayoritas bahkan hampir semua pasien stroke yang mengalami kelemahan pada otot. Dari sepuluh pasien stroke yang peneliti menemukan enam pasien stroke mengalami kelemahan otot sehingga pasien diberikan terapi latihan ROM pasif maupun aktif setiap hari baik oleh perawat maupun oleh ahli fisioterapi. Berdasarkan kejadian yang ada dilapangan pemberian terapi ROM oleh perawat belum secara maksimal dilakukan di RSUD Muhammad Sani karena dari bidang kesehatan yakni fisioterapi sudah memiliki program terapi untuk pasien stroke dan faktor lain yang membuat perawat belum bisa melaksanakan terapi ROM yaitu dikarenakan perawat memiliki kegiatan perawatan lain seperti melakukan terapi injeksi, menulis laporan, dan lain-lain.

Keterbatasan gerak yang dialami pasien stroke dapat diperparah dengan penurunan kekuatan otot yang terjadi pada pasien tersebut. Adanya keterbatasan pergerakan dan berkurangnya pemakaian sendi dapat memperparah kondisi muskuloskeletal dan mempercepat penurunan kekuatan otot dan fleksibilitas sendi pada pasien stroke. Penderita stroke yang mengalami hemiparese tentu membutuhkan penanganan segera terutama dalam hal rehabilitasi dan latihan gerak maka, penulis tertarik untuk melakukan penelitian tentang "Pengaruh Latihan ROM Terhadap Kekuatan Otot Pasien stroke Di Ruang Flamboyan RSUD Muhammad Sani Kabupaten Karimun.

\section{METODE PENELITIAN}

Jenis penelitian ini adalah penelitian Quasy Experiment dengan rancangan penelitian pre and post test without control. Sampel dalam penelitian ini terdiri dari 20 responden stroke dan data dianalisa menggunakan uji Wilcoxon Rank Test untuk eksteremitas atas dan Paired $T$ Test untuk ekstermitas bawah. Terapi ROM akan dilakukan dua kali dalam satu hari, dan untuk waktu pelaksanaannya 10-15 menit dalam sekali ROM, terapi ROM akan dilaksanakan dalam rentang waktu enam hari yang kemudian akan dievaluasi dengan lembar observasi skala kekuatan otot.

\section{HASIL DAN PEMBAHASAN}

Hasil analisis berdasarkan hasil penelitian terhadap 20 responden dan dapat dilihat pada uraian, sebagai berikut: 
Tabel 3.1 Deskripsi Hasil Kekuatan Otot Ekstermitas Atas Sebelum ROM di Ruang Flamboyan RSUD Muhammad Sani 2019.

\begin{tabular}{lll}
\hline Kekuatan Otot Ekstermitas Atas Sebelum ROM & f & \% \\
\hline (0)Tidak ada kontraksi & 3 & 15 \\
(1)Tampak kedutan otot dan sedikit kontraksi & 1 & 5 \\
(2)Gerakan aktif yang terbatas oleh gravitasi & 7 & 35 \\
(3)Gerakan aktif dapat melawan gravitasi & 8 & 40 \\
(4)Gerakan aktif dapat melawan gravitasi dan pemeriksa & 1 & 5 \\
\hline Total & $\mathbf{2 0}$ & $\mathbf{1 0 0}$ \\
\hline
\end{tabular}

Sumber: Data primer 2019

Berdasarkan table 3.1 didapatkan hasil kekuatan otot ekstermitas atas sebelum dilakukan ROM yaitu responden yang memiliki kekuatan otot tidak ada kontraksi otot sebanyak tiga orang (15\%), tampak kedutan otot dan sedikit kontraksi terdapat satu orang
$(5 \%)$, gerakan aktif yang terbatas oleh gravitasi terdapat tujuh orang $(35 \%)$, responden dengan gerakan aktif dapat melawan gravitasi terdapat delapan orang (40\%), dan responden dengan gerakan aktif dapat melawan gravitasi dan pemeriksa terdapat satu orang $(5 \%)$.

Tabel 3.2 Deskripsi Hasil Kekuatan Otot Ekstermitas Atas Sesudah ROM di Ruang Flamboyan RSUD Muhammad Sani 2019.

\begin{tabular}{lll}
\hline Kekuatan Otot Ekstermitas Atas Sesudah ROM & f & $\mathbf{\%}$ \\
\hline (1)Tampak kedutan otot dan sedikit kontraksi & 2 & 10 \\
(2)Gerakan aktif yang terbatas oleh gravitasi & 2 & 10 \\
(3)Gerakan aktif dapat melawan gravitasi & 5 & 25 \\
(4)Gerakan aktif dapat melawan gravitasi dan pemeriksa & 9 & 45 \\
(5)Kekuatan otot normal & 2 & 10 \\
\hline \multicolumn{1}{c}{ Total } & $\mathbf{2 0}$ & $\mathbf{1 0 0}$
\end{tabular}

Sumber: Data primer 2019

Berdasarkan table 3.2 didapatkan hasil kekuatan otot ekstermitas bawah sebelum dilakukan ROM yaitu responden yang memiliki kekuatan otot tampak kedutan otot dan sedikit kontraksi terdapat dua orang $(10 \%)$, gerakan aktif yang terbatas oleh gravitasi terdapat dua orang (10\%), gerakan aktif dapat melawan gravitasi terdapat lima orang (25\%), gerakan aktif dapat melawan gravitasi dan pemeriksa terdapat sembilan orang $(45 \%)$, dan responden dengan kekuatan otot normal terdapat dua orang (10\%). 
Tabel 3.3 Deskripsi Hasil Kekuatan Otot Ekstermitas Bawah

Sebelum ROM di Ruang Flamboyan RSUD Muhammad Sani 2019.

\begin{tabular}{lll}
\hline Kekuatan Otot Ekstermitas Bawah Sebelum ROM & f & \% \\
\hline (0)Tidak ada kontraksi & 1 & 5 \\
(1)Tampak kedutan otot dan sedikit kontraksi & 2 & 10 \\
(2)Gerakan aktif yang terbatas oleh gravitasi & 6 & 30 \\
(3)Gerakan aktif dapat melawan gravitasi & 5 & 25 \\
(4)Gerakan aktif dapat melawan gravitasi dan pemeriksa & 5 & 25 \\
(5)Kekuatan otot normal & 1 & 5 \\
\hline Total & $\mathbf{2 0}$ & $\mathbf{1 0 0}$
\end{tabular}

Sumber: Data primer 2019

Berdasarkan table 3.3 didapatkan hasil kekuatan otot ekstermitas atas sesudah dilakukan ROM yaitu responden yang memiliki kekuatan otot tidak ada kontraksi otot sebanyak satu orang $(5 \%)$, tampak kedutan otot dan sedikit kontraksi terdapat dua orang (10 $\%)$, gerakan aktif yang terbatas oleh gravitasi terdapat enam orang $(30 \%)$, gerakan aktif dapat melawan gravitasi terdapat lima orang $(25 \%)$, gerakan aktif dapat melawan gravitasi dan pemeriksa terdapat lima orang $(25 \%)$, dan responden dengan kekuatan otot normal terdapat satu orang $(5 \%)$

Tabel 3.4 Deskripsi Hasil Kekuatan Otot Ekstermitas Bawah Sesudah ROM di Ruang Flamboyan RSUD Muhammad Sani 2019.

\begin{tabular}{lll}
\hline Kekuatan Otot Ekstermitas Bawah Sesudah ROM & f & $\mathbf{\%}$ \\
\hline (1)Tampak kedutan otot dan sedikit kontraksi & 2 & 10 \\
(2)Gerakan aktif yang terbatas oleh gravitasi & 1 & 5 \\
(3)Gerakan aktif dapat melawan gravitasi & 5 & 25 \\
(4)Gerakan aktif dapat melawan gravitasi dan pemeriksa & 7 & 35 \\
(5)Kekuatan otot normal & 5 & 25 \\
\hline \multicolumn{1}{c}{ Total } & $\mathbf{2 0}$ & $\mathbf{1 0 0}$
\end{tabular}

Sumber: Data primer 2019

Berdasarkan table 3.4 didapatkan hasil kekuatan otot ekstermitas bawah sesudah dilakukan ROM yaitu responden yang memiliki kekuatan otot tampak kedutan otot dan sedikit kontraksi terdapat dua orang (10\%), gerakan aktif yang terbatas oleh gravitasi terdapat satu orang (5\%), gerakan aktif dapat melawan gravitasi terdapat lima orang $(25 \%)$, gerakan aktif dapat melawan gravitasi dan pemeriksa terdapat tujuh orang (35\%), dan responden dengan kekuatan otot normal terdapat lima orang $(25 \%)$. 
Tabel 3.5 Pengaruh latihan ROM terhadap kekuatan otot ekstermitas atas pada pasien stroke di Ruang Flamboyan RSUD Muhammad Sani 2019

\begin{tabular}{ccccc}
\hline Kekuatan Otot & N & Median & Min-Max & p-value \\
\hline Pre Test Ekstermitas Atas & 20 & 2 & $0-4$ & \multirow{2}{*}{0,000} \\
Post Test Ekstermitas Atas & 20 & 4 & $1-5$ & \\
\hline
\end{tabular}

Sumber: Data primer 2019

Berdasarkan table 3.5 didapatkan hasil uji Wilcoxon Rank Test yaitu nilai median pada ekstermitas atas sebelum dilakukan ROM sebesar dua yang berarti kekuatan otot pada kategori Gerakan aktif yang terbatas oleh gravitasi sedangkan nilai median pada ekstermitas atas sesudah dilakukan ROM sebesar empat yang berarti kekuatan otot pada kategori Gerakan aktif dapat melawan gravitasi dan pemeriksa. Sebelum dilakukan ROM kekuatan otot terendah adalah nol dan tertinggi empat sedangkan setelah dilakukan ROM nilai terendahyaitu satu dan tertinggi lima. Dari tabel diatas dapat dilihat bahwa signifikansi sebesar 0,000 sehingga dapat dinyatakan bahwa $\mathrm{H}_{1}$ diterima atau ada pengaruh latihan ROM terhadap kekuatan otot ekstermitas atas pada pasien stroke di Ruang Flamboyan RSUD Muhammad Sani.

Menurut Lewis (2007) dalam penelitian Derison dan
Surani (2016) Mengemukakan bahwa atropi otot karena kurangnya aktivitas dapat terjadi hanya dalam waktu kurang dari satu bulan setelah terjadinya serangan stroke. Namun dengan pemberian latihan range of motion dengan rutin dan sedini mungkin pada bagian tubuh yang mengalami kelemahan ataupun kekakuan sendi, akan memberikan perubahan yang berfungsi melemaskan sendisendi yang telah kaku.

Latihan range of motion dilakukan dengan tujuan untuk mempertahankan atau meningkatkan kekuatan otot, memelihara mobilitas persendian, merangsang sirkulasi darah dan mencegah kelainan bentuk. Jaringan otot yang memendek akan memanjang secara perlahan apabila dilakukan latihan range of motion dan jaringan otot akan mulai beradaptasi untuk mengembalikan panjang otot kembali normal (Murtaqib, 2013). 
Tabel 3.6 Pengaruh latihan ROM terhadap kekuatan otot ekstermitas bawah pada pasien stroke di Ruang Flamboyan RSUD Muhammad Sani 2019

\begin{tabular}{ccccc}
\hline Kekuatan Otot & Mean & N & $\begin{array}{c}\text { Standar } \\
\text { Deviasi }\end{array}$ & p-value \\
\hline Pre Test Ekstermitas Bawah & 2,7 & 20 & 1,26 & \\
Post Test Ekstermitas Bawah & 3,6 & 20 & 1,23 & 0,000 \\
\hline
\end{tabular}

Sumber: Data primer 2019

Berdasarkan table 3.6 didapatkan hasil uji Paired $\mathrm{T}$ Test yaitu hasil rata rata kekuatan otot ekstermitas bawah responden sebelum dilakukan ROM didapatkan mean 2,7 dengan standar deviasi sebesar 1,26 dan pada pengukuran akhir sesudah diberikan terapi didapatkan mean 3,6 dengan standar deviasi sebesar 1,23. Dari tabel diatas dapat dilihat bahwa signifikansi sebesar 0,000 dimana nilai signifikansi lebih kecil dari 0,05 sehingga dapat dinyatakan bahwa $\mathrm{H} 1$ diterima atau ada pengaruh latihan ROM terhadap kekuatan otot ekstermitas bawah pada pasien stroke di Ruang Flamboyan RSUD Muhammad Sani.

Hasil penelitian ini juga didukung oleh penelitian yang dilakukan oleh Hasyim (2013) yang mengatakan bahwa latihan ROM yang dilakukan sedini mungkin dan dilakukan dengan benar dan secara terus-menerus akan memberikan dampak pada fleksibilitas sendi, kekuatan otot dan kemampuan fungsional pasien.

Menurut penelitian Irdawati (2012) menyatakan bahwa latihan pergerakan khususnya rentang gerak bagi penderita stroke dapat meningkatkan kemandirian pasien. Hal ini dikarenakan dengan latihan gerak maka otot pun akan bermobilisasi. Mobilisasi otot dapat mencegah kekakuan otot, melancarkan sirkulasi darah, akan meningkatkan massa otot. Apabila hal ini dilakukan dengan rutin maka toleransi otot untuk melakukan gerakan pun akan meningkat (Christian, 2008).

ROM merupakan pergerakan persendian sesuai dengan gerakan yang memungkinkan terjadinya kontraksi dan pergerakan otot baik secara pasif maupun aktif (Winstein et al., 2016). Gerakan berulang kali dan terfokus dapat membangun koneksi baru antara motor system dan mengaktifkan spinal motorneuron adalah dasar pemulihan pada Stroke (Lang and Beebe, 2009).

Sesuai dengan teori Sherwood (2012) yang menjelaskan pengaruh aktivitas terhadap kekuatan otot adalah pengikatan molekul miosin dan aktin di jembatan silang menyebabkan kontraksi serat otot yang memerlukan energi. Setiap molekul aktin memiliki suatu tempat pengikatan khusus untuk melekatnya jembatan silang miosin. Jika suatu otot tidak digunakan maka kandungan aktin dan myosin nya berkurang, seratnya menjadi 
lebih kecil, dan karenanya menjadi atrofi (massanya berkurang) dan lebih lemah.

Dalam penelitian Anita (2018) mengatakan bahwa pasien Stroke harus di mobilisasi sedini mungkin. Salah satu mobilisasi dini yang dapat segera dilakukan adalah pemberian latihan range of motion yang bertujuan untuk meningkatkan kemandirian pasien pasca Stroke. Menurut Peneliti Range of motion (ROM) jika dilakukan sedini mungkin dan dilakukan dengan benar dan secara terusmenerus akan memberikan dampak pada kekuatan otot.

\section{SIMPULAN}

Berdasarkan hasil penelitian didapatkan kesimpulan yaitu sebelum dilakukan ROM paling banyak ekstermitas atas responden dengan kekuatan otot gerakan aktif dapat melawan gravitasi terdapat delapan orang (40\%), pada ekstermitas bawah sebelum ROM didapatkan kekuatan otot paling banyak gerakan aktif yang terbatas oleh gravitasi terdapat enam orang (30\%), kekuatan otot ekstermitas atas sesudah dilakukan ROM yaitu paling banyak responden yang memiliki kekuatan otot gerakan aktif dapat melawan gravitasi dan pemeriksa terdapat sembilan orang $(45 \%)$, dan kekuatan pada ekstermitas bawah sesudah dilakukan ROM yaitu paling banyak responden yang memiliki kekuatan otot gerakan aktif dapat melawan gravitasi dan pemeriksa terdapat tujuh orang (35\%). Dari hasil penelitian didapatkan nilai $p$ value (ekstermitas atas $p$ value $=$
0,000 , ekstermitas bawah $p$ vaule $=0,001$.

Dari hasil penelitian maka hendaknya pelayanan keperawatan perlu mengadakan pelatihan tenaga keperawatan secara terencana, dan berkesinambungan terkait dengan latihan ROM, mewujudkan discharge planning program pada pasien Stroke untuk menjamin latihan dirumah, serta mengadakan program khusus memberikan bimbingan dan latihan untuk keluarga caracara melakukan latihan ROM dirumah pada pasien Stroke sebagai salah satu upaya mengurangi kecacatan dan meningkatkan fungsi kemandirian pasien sehingga dengan demikian pasien dapat melakukan aktivitas sehari-hari serta dapat memenuhi kebutuhan dasar. Latihan ROM merupakan satu hal yang sangat diperlukan untuk meningkatkan kekuatan otot pada pasien Stroke dimana semakin sering melakukan ROM maka kekuatan otot akan semakin bertambah

\section{UCAPAN TERIMAKASIH}

Penelitian ini disusun atas kerjasama dan berkat bantuan dari berbagai pihak. Pada kesempatan ini penyusun mengucapkan terima kasih kepada:

1. Prof. dr. Fadil Oenzil. PhD, Sp.GK, selaku Ketua Sekolah Tinggi Ilmu Kesehatan Awal Bros Batam beserta seluruh jajarannya.

2. Bapak Bupati Karimun dan Kepala Bagian Kepegawaian Kabupaten 
Karimun yang telah memberikan kesempatan peneliti untuk melanjutkan pendidikan.

3. Kepala Dinas Kesehatan Kabupaten Karimun yang telah memberikan kesempatan peneliti untuk melanjutkan pendidikan.

4. Direktur RSUD Muhammad Sani yang telah memberikan kesempatan peneliti untuk melakukan penelitian

\section{DAFTAR PUSTAKA}

American Heart Association. (2014). A Guideline for Healthcare Professionals From the American Heart Association / American Stroke Association, Retrieved 2015, From American Heart Association

American Heart Association. (2016) Cardiovascular Disease : A Costly Burden For America Projections Through 2035. The American Heart Association Office of Federal Advocacy : Washington DC;2016.

Anita Fransiska, Pongantung Henny, Ada Putri Veni, Hingkam Vhiola. (2018). Pengaruh Latihan Range Of Motion Terhadap Rentang Gerak Sendi Ekstremitas Atas Pada Pasien Pasca Stroke Di Makassar. Journal Islamic Nursing. Vol 3, No 1 (2018). Doi: Https://Doi.
Org/10. 24252/Join .V3i1. 5703

Beebe, Ja \& Lang, Ce. (2009). Active Range Of Motion Predicts Upper Extremity Function Three Months Post-Stroke. Stroke 40(5), 1772-1779

Hardwick, Dd \& Lang, Ce. (2012). Scapular And Humeral Movement Patterns Of People With Stroke During Range Of Motion Exercises. Journal Neurol Physical Therapy . 35 (1), 18-25Anita (2018)

Irfan, Muhammad. (2010). Fisioterapi bagi insan stroke . Yogyakarta: Graha Ilmu

Levine, G. Peter. (2008). Stronger After Stroke Your Roadmap To Recovery. Demos Medical Publishing.

Mawarti, H., \& Farid. (2012). Pengaruh latihan ROM (Range Of Motion) pasif terhadap peningkatan kekuatan otot pada pasien stroke dengan hemiparase. http://www.journal.unipdu. ac.id/index.php/eduhealth/ article/

Potter\&Perry.(2009). Fundament al Of Nursing, Buku 1, Edisi : 7, Salemba Medika : Jakarta

Sherwood, L., (2012). Fisiologi manusia dari sel ke sistem. Jakarta: EGC 
Winstein, C. J., Stein, J., Arena,

R., Bates, B., Cherney, L.

R., Cramer, S. C., ...

Zorowi , R. D. (2016).

Guidelines for Adult

Stroke Rehabilitation and

Recovery: A Guideline for

Healthcare Professionals

from the American Heart

Association/American

Stroke Association. Stroke.

47(6): e98-e 169.

Wirawan, R. P. (2009).

Rehabilitasi Stroke Pada

Pelayanan Kesehatan

Primer. Majelis

Kedokteran Indonesia, Vol

59 Nomor 2 , 